\title{
Differences in Negative T Waves Between Takotsubo Cardiomyopathy and Reperfused Anterior Acute Myocardial Infarction
}

\author{
Masami Kosuge, MD; Toshiaki Ebina, MD; Kiyoshi Hibi, MD; Noriaki Iwahashi, MD; \\ Kengo Tsukahara, MD; Mitsuaki Endo, MD; Nobuhiko Maejima, MD; \\ Zenko Nagashima, MD; Hiroyuki Suzuki, MD; Satoshi Morita, PhD; \\ Satoshi Umemura, MD; Kazuo Kimura, MD
}

\begin{abstract}
Background: In both takotsubo cardiomyopathy (TC) and reperfused anterior acute myocardial infarction (AMI), negative T waves commonly appear on the ECG in the subacute phase. This study aimed to clarify the ECG differences between these diseases.

Methods and Results: We compared the ECGs with the greatest amplitude of negative T wave from 34 patients with TC and 237 patients with a first reperfused anterior AMI who were admitted within $6 \mathrm{~h}$ of symptom onset and who had no abnormal Q-waves on discharge ECG. Time from symptom onset to recording the ECG did not differ between TC and anterior AMI (2.4 \pm 1.5 vs. $2.1 \pm 2.0$ days, $P=0.48)$. TC was associated with a greater maximal amplitude of negative $T$ wave $(1.00 \pm 0.44$ vs. $0.79 \pm 0.46 \mathrm{mV}, P=0.044)$, and a greater number of leads with negative $T$ waves (9.5 \pm 1.0 vs. $6.0 \pm 2.1, P<0.001)$. Negative $T$ waves were consistently observed in leads $-a V_{R}$ and $V_{4-6}$, whereas negative $\mathrm{T}$ waves were rare in lead $\mathrm{V}_{1}$ in $\mathrm{TC}$. Negative $\mathrm{T}$ waves in lead $-\mathrm{a} \mathrm{V}_{\mathrm{R}}$ (ie, positive $\mathrm{T}$ waves in lead $a V_{R}$ ) and no negative $T$ waves in lead $V_{1}$ identified $T C$ with $94 \%$ sensitivity and $95 \%$ specificity, representing the highest diagnostic accuracy.
\end{abstract}

Conclusions: During the subacute phase, deeper negative T waves were more frequently and broadly distributed, particularly around leads facing the apical region, in TC than in reperfused anterior AMI. (Circ J 2012; 76: 462468)

Key Words: Acute myocardial infarction; Electrocardiogram; Takotsubo cardiomyopathy

$\mathbf{T}$ akotsubo cardiomyopathy (TC) is a recently recognized novel cardiac syndrome characterized by STsegment elevation with subsequent negative $\mathrm{T}$ waves on the electrocardiogram (ECG), elevated cardiac enzymes, and transient left ventricular apical ballooning without obstructive coronary disease. ${ }^{1-14}$ Because the clinical features of TC mimic those of anterior acute myocardial infarction (AMI) with occlusion of the left anterior descending (LAD) coronary artery, differentiation of these 2 diseases can be challenging, but has an important role in the selection of an appropriate treatment strategy. The 12-lead ECG is the simplest, most widely available, initial clinical diagnostic test. ${ }^{15}$ Previous studies, including ours, assessing electrocardiographic differences between these 2 diseases have focused mainly on the acute phase when ST-segment elevation is observed, ${ }^{6-8}$ because differential diagnosis is essential for deciding whether reperfusion therapy is required. However, previous studies have reported that negative $\mathrm{T}$ waves have already occurred on the ECG at the time of presentation in an appreciable number of patients with TC., ${ }^{2,12}$ Subsequent ECG changes after the acute phase (ie, the development of negative $\mathrm{T}$ waves after resolution of ST-segment elevation) have also been shown to be similar in both TC and reperfused anterior AMI.$^{10}$ Electrocardiographic criteria that can be used to differentiate these 2 diseases in this phase remain to be elucidated. In most patients with TC, left ventricular dysfunction improves rapidly and dramatically. There is a risk of misdiagnosing TC, in which ST-segment elevation resolves and negative T waves develop on initial ECG, as anterior AMI with complete spontaneous reperfusion and subsequent recovery of stunned myocardium, ${ }^{5}$ potentially leading to inappropriate treatment at presentation and subsequently. Some, ${ }^{5,16}$ but not all, ${ }^{17,18}$ studies have suggested that the pathophysiological mechanism of TC involves spontaneously aborted myocardial infarction (MI), resulting

Received September 13, 2011; revised manuscript received October 15, 2011; accepted October 26, 2011; released online December 2,

2011 Time for primary review: 21 days

Division of Cardiology, Yokohama City University Medical Center, Yokohama, Japan

Mailing address: Masami Kosuge, MD, Division of Cardiology, Yokohama City University Medical Center, 4-57 Urafune-cho, Minami-ku,

Yokohama 232-0024, Japan. E-mail: masami-kosuge@ pop06.odn.ne.jp

ISSN-1346-9843 doi:10.1253/circj.CJ-11-1036

All rights are reserved to the Japanese Circulation Society. For permissions, please e-mail: cj@j-circ.or.jp 


\begin{tabular}{lccc|}
\hline Table 1. Baseline Characteristics of the Study Subjects & & \\
& TC $(\mathbf{n}=\mathbf{3 4})$ & Anterior AMI $(\mathbf{n = 2 3 7})$ & P value \\
Age (years) & $70 \pm 11$ & $61 \pm 11$ & $<0.001$ \\
Women & $29(85 \%)$ & $49(21 \%)$ & $<0.001$ \\
Risk factors & & & \\
$\quad$ Diabetes mellitus & $3(9 \%)$ & $57(24 \%)$ & 0.048 \\
Hypertension & $15(44 \%)$ & $99(42 \%)$ & 0.85 \\
Hyperlipidemia & $5(15 \%)$ & $77(33 \%)$ & 0.045 \\
Smoking & $4(12 \%)$ & $148(62 \%)$ & $<0.001$ \\
Killip class $\geq 2$ on admission & $4(12 \%)$ & $7(3 \%)$ & 0.036 \\
Initial LVEF (\%) & $41 \pm 9$ & $52 \pm 10$ & $<0.001$ \\
Peak creatine kinase (IU/L) & $384 \pm 398$ & $1,505 \pm 921$ & $<0.001$ \\
Peak creatine kinase-MB (IU/L) & $36 \pm 18$ & $131 \pm 102$ & $<0.001$ \\
\hline
\end{tabular}

Data are mean value \pm SD or number of patients (\%).

TC, takotsubo cardiomyopathy; AMI, acute myocardial infarction; LVEF, left ventricular ejection fraction.

from an acute atherothrombotic event with rapid and complete lysis of thrombus in the LAD coronary artery. In this study, we assessed the electrocardiographic differences, especially negative $\mathrm{T}$ waves, between TC and reperfused anterior AMI in the subacute phase. Such differences may further provide important clues to our understanding of the pathophysiologic mechanisms of these 2 diseases and facilitate differential diagnosis. In TC, transient abnormal Q-waves often appear in the acute phase and usually disappear promptly, followed by the reappearance of $\mathrm{R}$ waves.,11 Our study group therefore included patients with reperfused anterior AMI, particularly those with no abnormal Q-waves on discharge ECG, whose characteristics may be very similar to those of patients with TC.

\section{Editorial p 305}

\section{Methods}

\section{Patients}

Clinical features and electrocardiographic findings were retrospectively compared between 34 consecutive patients with TC and 237 consecutive patients with anterior AMI who were admitted to hospital within $6 \mathrm{~h}$ of symptom onset. Patients with cardiogenic shock and conditions precluding the evaluation of ST-segment changes on ECG (ie, complete left or right bundle branch block, left ventricular hypertrophy, ventricular pacing, atrial fibrillation or flutter, electrolyte abnormalities, metabolic disease, or treatment with drugs potentially affecting ECG) were excluded from this study. All patients gave informed consent and the study protocol was approved by the institution's ethics committee.

TC Group Patients who had an acute cardiac event associated with symptoms suggesting TC, such as dyspnea, chest pain/discomfort, or palpitations, were studied. ${ }^{2-4,12,13}$ All patients underwent coronary angiography (CAG) during hospitalization. Emergency CAG was performed in 26 patients (76\%) and emergency left ventriculography in $24(71 \%)$. TC was diagnosed according to the following criteria, which incorporated the proposed Mayo criteria for the clinical diagnosis of TC $(1-4),{ }^{3}$ as well as an additional previously proposed criterion (5):11 (1) transient akinesis or dyskinesis of the left ventricular apical and mid-ventricular segments with regional wall motion abnormalities extending beyond a single epicardial vascular distribution; (2) absence of obstructive coronary disease or angiographic evidence of acute plaque rupture; (3) new electrocardiographic abnormalities (ST-segment eleva- tion or T wave inversion); (4) absence of recent significant head trauma, intracranial bleeding, pheochromocytoma, myocarditis, and hypertrophic cardiomyopathy; and (5) the prompt normalization of systolic function after presentation. All patients had ST-segment elevation $>0.1 \mathrm{mV}$ in at least 2 contiguous precordial leads on admission ECG.

Anterior AMI Group The diagnosis of anterior AMI was based on typical chest pain and a rise in serum creatine kinaseMB level in accordance with the universal definition of MI, ${ }^{19}$ as well as precordial ST-segment elevation $>0.1 \mathrm{mV}$ in at least 2 contiguous precordial leads on admission ECG. All patients underwent CAG immediately after admission, and the presence of obstruction, severe stenosis, or intracoronary thrombus in the LAD coronary artery was documented. The allocation of reperfusion therapy was left to the discretion of the physician in charge, and successful reperfusion, defined as a Thrombolysis In Myocardial Infarction (TIMI) ${ }^{20}$ grade 3, was obtained by fibrinolysis in 54 patients and by percutaneous coronary intervention in 183. Emergency left ventriculography was performed in 192 patients $(81 \%)$. All patients had no history of previous MI and no abnormal Q-waves in leads $\mathrm{V}_{2,3}$ on discharge ECG. ${ }^{19}$

\section{ECG Evaluation}

A 12-lead ECG was recorded on admission and at 3-h intervals during the first $24 \mathrm{~h}$, at 6 -h intervals for the next 2 days, and then daily until discharge at a paper speed of $25 \mathrm{~mm} / \mathrm{s}$ and an amplification of $10 \mathrm{~mm} / \mathrm{mV}$. ECGs with negative $\mathrm{T}$ waves of greatest amplitude after admission were evaluated. All ECGs were examined by a single cardiologist who was blinded to all other clinical data. ST-segment deviation was measured manually to the nearest $0.5 \mathrm{~mm}, 80 \mathrm{~ms}$ after the $\mathrm{J}$ point. ST-segment deviation was considered present if deviation was $>0.05 \mathrm{mV}$ in limb leads and $>0.1 \mathrm{mV}$ in precordial leads. ${ }^{21}$ Negative $\mathrm{T}$ waves were considered present if the depth was $\geq 0.1 \mathrm{mV} .{ }^{11,22}$ In this study, the anatomically contiguous Cabrera sequence (III, $\mathrm{aV}_{\mathrm{F}}, \mathrm{II},-\mathrm{a} V_{\mathrm{R}}, \mathrm{I}$, and $\mathrm{aV}_{\mathrm{L}}$ ) was used to display the limb leads in accordance with current international recommendations for the clinical interpretation of ECG. ${ }^{23,24}$ QT interval was defined as the interval from the beginning of the QRS complex to the end of the T wave. If $U$ waves were present, QT interval was measured to the nadir of the curve between $\mathrm{T}$ and $\mathrm{U}$ waves. QT interval was corrected for heart rate by Bazett's formula. ${ }^{25}$ 


\begin{tabular}{|lccc|}
\hline \multicolumn{2}{|l|}{ Table 2. Electrocardiographic Findings of the Study Subjects } & & \\
& TC $(\mathbf{n}=\mathbf{3 4})$ & Anterior AMI $(\mathbf{n}=\mathbf{2 3 7})$ & P value \\
RR interval (ms) & $772 \pm 149$ & $788 \pm 142$ & 0.62 \\
Abnormal Q-wave & $10(29 \%)$ & $59(25 \%)$ & 0.54 \\
Maximal ST-segment elevation (mV) & $0.17 \pm 0.19$ & $0.22 \pm 0.12$ & 0.037 \\
No. of leads with ST-segment elevation & $2.3 \pm 2.6$ & $2.8 \pm 2.5$ & 0.19 \\
Maximal QTc interval (ms) & $642 \pm 93$ & $586 \pm 81$ & 0.001 \\
Maximal amplitude of negative T waves (mV) & $1.00 \pm 0.44$ & $0.79 \pm 0.46$ & 0.044 \\
No. of leads with negative T wave & $9.5 \pm 1.0$ & $6.0 \pm 2.1$ & $<0.001$ \\
\hline
\end{tabular}

Data are mean value \pm SD or number of patients (\%).

AMI, acute myocardial infarction; TC, takotsubo cardiomyopathy.

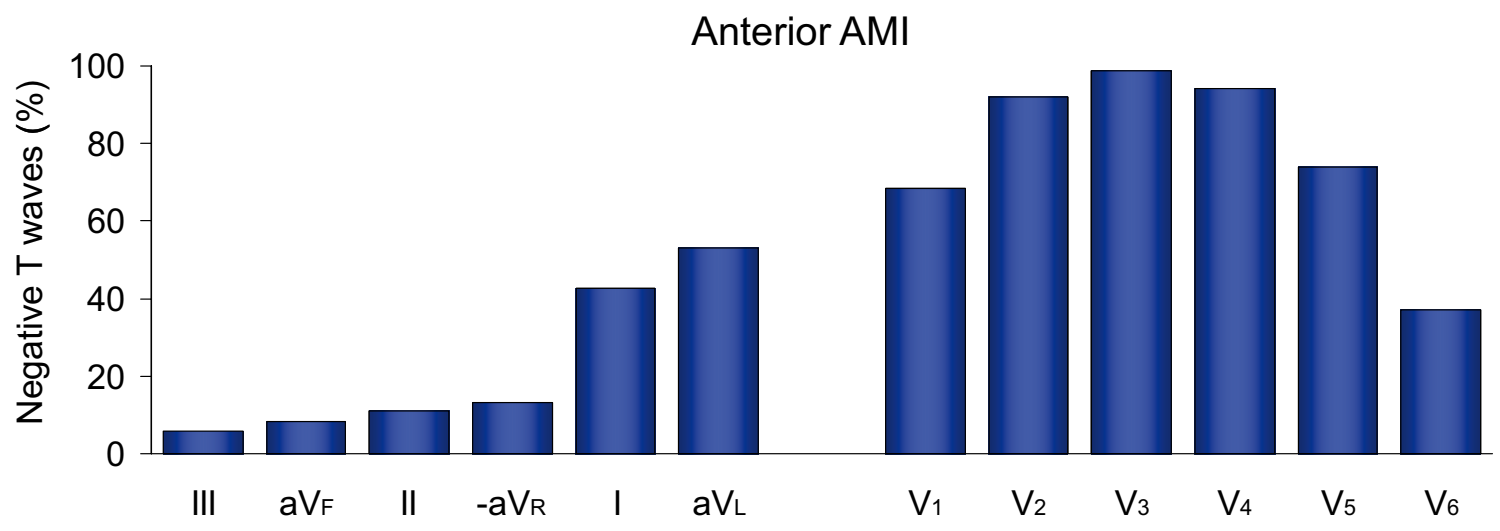

Takotsubo cardiomyopathy

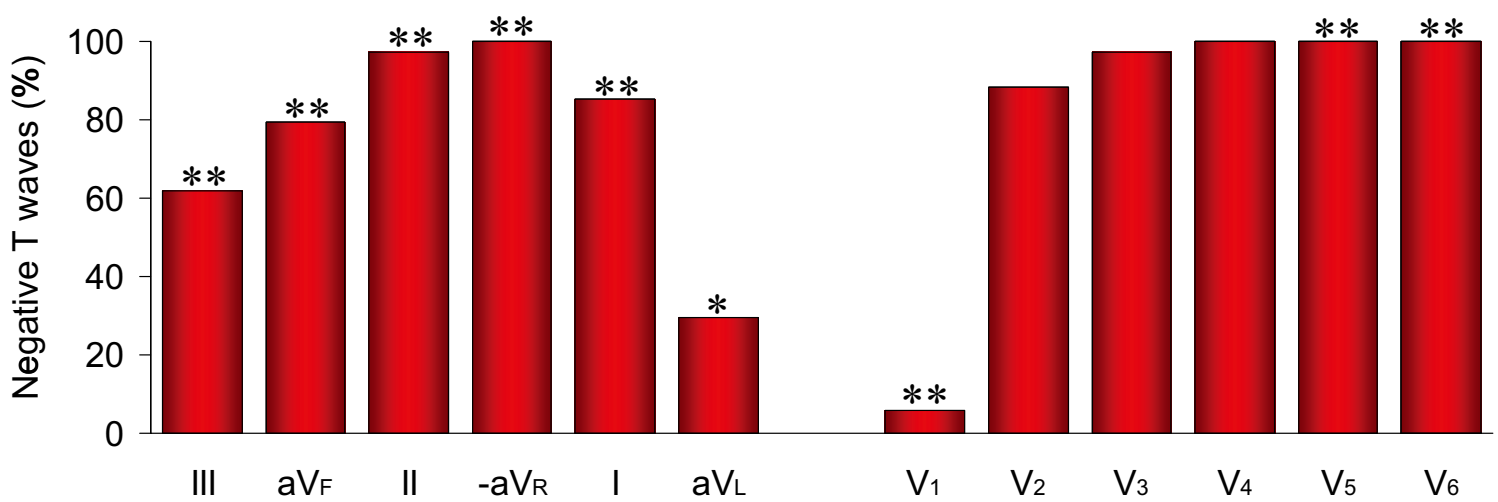

Figure 1. Prevalence of negative T waves in patients with takotsubo cardiomyopathy (TC) and those with anterior acute myocardial infarction (AMI). In the limb leads, the prevalence of negative T waves gradually decreased from leads aV $\mathrm{L}$ to III in patients with anterior AMI. In contrast, a high prevalence of negative T waves centered around lead -aV $\mathrm{R}$ in TC. In the precordial leads, negative $T$ waves were distributed primarily around leads $V_{2-4}$ in patients with anterior $A M I$, but appeared in leads $V_{4-6}$ in all patients with TC. ${ }^{*} \mathrm{P}<0.05,{ }^{* *} \mathrm{P}<0.01$ vs. anterior AMI.

\section{Cardiac Enzyme Study}

Blood samples for measurement of creatine kinase levels were obtained on admission and at 3 -h intervals during the first $24 \mathrm{~h}$, at 6-h intervals for the next 2 days, and then daily until discharge.

\section{Statistical Analysis}

Continuous data are expressed as means $\pm \mathrm{SD}$, and categorical data are expressed as percentages. Two-tailed unpaired t-test or the Mann-Whitney U statistical test was used to compare continuous variables. Chi-square analysis was used to compare categorical variables. Differences were considered statistically significant at $\mathrm{P}<0.05$.

\section{Results}

\section{Study Group}

The baseline characteristics of the subjects are shown in 
Table 3. Predictive Value of Electrocardiographic Variables for the Diagnosis of Takotsubo Cardiomyopathy

Presence of positive $T$ waves in lead $\mathrm{aV} \mathrm{V}_{\mathrm{R}}$ (=Presence of negative $T$ waves in lead $-a V_{R}$ )

Sensitivity

Specificity

PPV

NPV

Predictive

Absence of negative $T$ waves in lead $V_{1}$

Presence of positive $T$ waves in lead $a V_{R}$

and absence of negative $T$ waves in lead $V_{1}$

$\begin{array}{rllll}100 \% & 87 \% \text { ** } & 52 \%{ }^{*} & 100 \% & 89 \%^{*} \\ 94 \% & 68 \% \text { ** } & 30 \% \text { ** } & 99 \% & 72 \% \text { ** } \\ 94 \% & 95 \% & 71 \% & 99 \% & 94 \%\end{array}$

${ }^{*} P<0.05,{ }^{* *} P<0.01$ vs. presence of positive $T$ waves in lead $a V_{R}$ and absence of negative $T$ waves in lead $V_{1}$.

PPV, positive predictive value; NPV, negative predictive value.
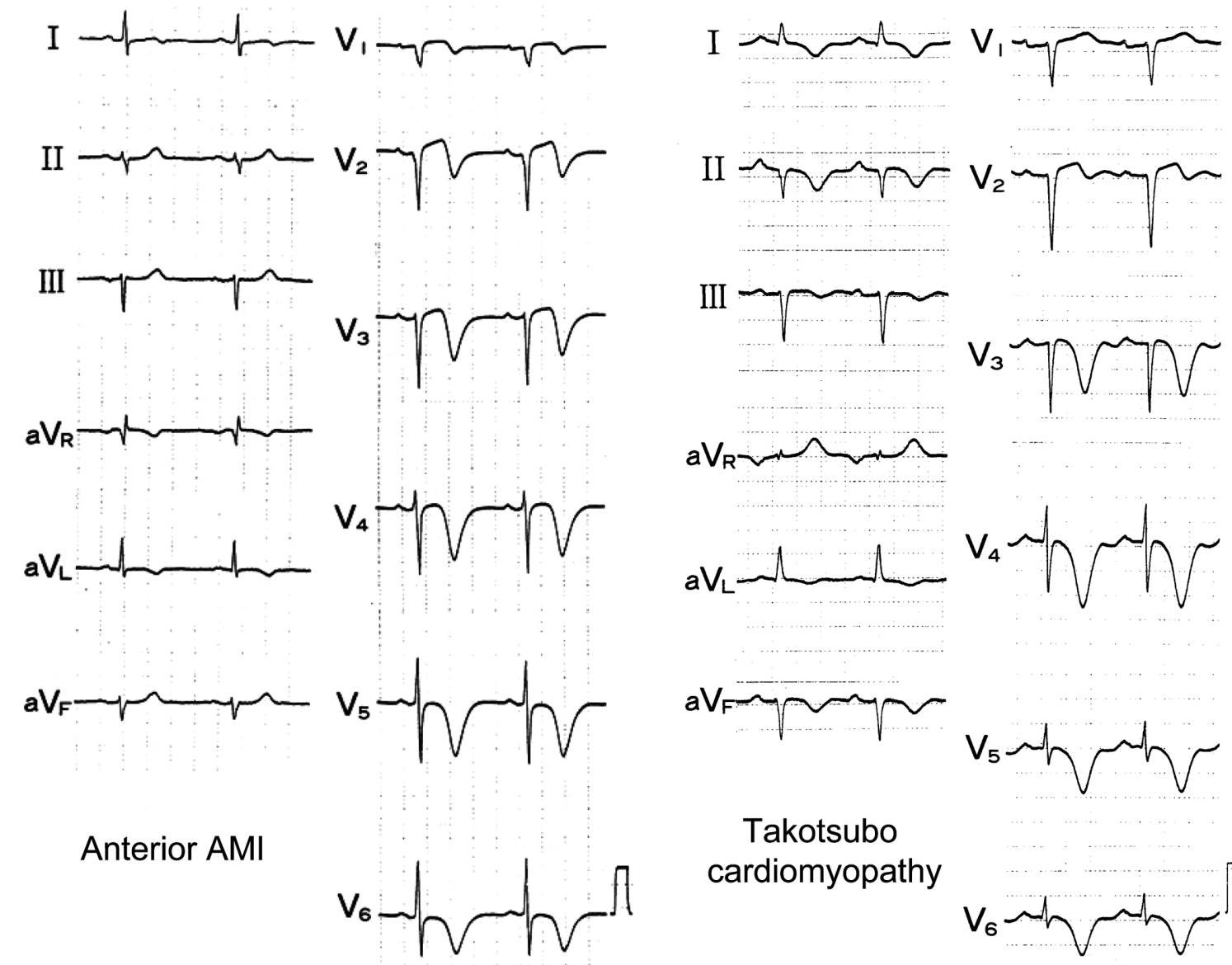

Takotsubo

cardiomyopathy

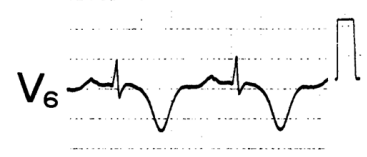

Figure 2. Representative ECGs of takotsubo cardiomyopathy (TC) and anterior acute myocardial infarction (AMI). Left (anterior AMI): negative $T$ waves were observed in leads I, aV L, and $V_{1-6}$. Right (TC): negative $T$ waves were observed in leads I, II, III, aV L, $a V_{F}$, and $V_{2-6}$. Positive $T$ waves were observed in leads $a V_{R}$ and $V_{1}$. The calibration indicates $1.0 \mathrm{mV}$.

Table 1. Patients with TC were older, more likely to be female, and had lower rates of diabetes mellitus, hyperlipidemia, and smoking, a higher rate of Killip class $\geq 2$ on admission, and a longer time from symptom onset to admission than did patients with anterior AMI (TC vs. anterior AMI: $3.3 \pm 2.4$ vs. $2.2 \pm 2.0 \mathrm{~h}$, $\mathrm{P}<0.001)$. Among 237 patients with anterior AMI, 35 (15\%) had multivessel disease. The initial left ventricular ejection fraction, which was evaluated on right anterior oblique views of left ventriculograms, was significantly lower in patients with TC; however, peak creatine kinase and creatine kinaseMB levels were significantly lower in patients with TC.

\section{ECG Findings}

Time from symptom onset to recording ECGs with the greatest amplitude of negative $\mathrm{T}$ waves did not differ significantly between the TC and anterior AMI groups (2.4 \pm 1.5 vs. $2.1 \pm 2.0$ days, $\mathrm{P}=0.48$ ). Electrocardiographic findings are presented in Table 2. RR intervals and the frequencies of abnormal Q-waves did not differ significantly between TC and anterior AMI. TC was associated with a smaller maximal ST-segment elevation and a longer maximal QTc interval. TC was also associated with a greater maximal amplitude of negative $T$ waves and a greater number of leads with negative $\mathrm{T}$ waves. The prevalence of negative $\mathrm{T}$ waves is shown in Figure 1. 
Negative $T$ waves were consistently observed in leads $-\mathrm{aV}_{\mathrm{R}}$ and $V_{4-6}$, whereas negative $T$ waves were rare in lead $V_{1}$ in TC. As compared with anterior AMI, TC was more frequently associated with negative $\mathrm{T}$ waves in leads III, $\mathrm{aVF}$, II, $-\mathrm{aV}$, I, and $V_{5,6}$, but was less frequently associated with negative $T$ waves in leads $a V_{L}$ and $V_{1}$, especially lead $V_{1}$. The combination of the presence of negative $\mathrm{T}$ waves in lead $-\mathrm{aVR}$ (ie, positive $T$ waves in lead $a V_{R}$ ) and the absence of negative $T$ waves in lead $\mathrm{V}_{1}$ was observed in $94 \%$ of the patients with TC, as compared with only $5 \%$ of those with anterior AMI $(\mathrm{P}<0.001)$. The combination of these 2 findings provided the highest ability to differentiate TC from anterior AMI, as compared with other electrocardiographic findings. Table 3 shows the sensitivity, specificity, positive and negative predictive values, and predictive accuracy of ECG findings for the diagnosis of TC. For other continuous electrocardiographic variables not shown in the Table, no cut-off points were found to discriminate between TC and anterior AMI. Figure 2 shows representative ECGs for a patient from each group.

\section{Discussion}

This study showed that negative $\mathrm{T}$ waves progressively developed in association with QT prolongation in both TC and reperfused anterior AMI during the subacute phase and were especially prominent in the former. In TC, deeper negative T waves were more frequently and broadly distributed, particularly around leads facing the apical region, suggesting differences in the underlying pathologic characteristics of the myocardium between the 2 diseases. TC might be associated with more extensive and more viable, but sympathetically denervated, myocardium centered around the apical region. Furthermore, the different distribution of negative $\mathrm{T}$ waves of greatest amplitude on ECGs was useful for differentiating these 2 diseases. The presence of negative $T$ waves in lead $-a V_{R}$ (ie, positive $T$ waves in lead $a V_{R}$ ) combined with the absence of negative $\mathrm{T}$ waves in lead $\mathrm{V}_{1}$ strongly suggested $\mathrm{TC}$.

TC has been increasingly reported worldwide, and the need to include it in the differential diagnosis of anterior AMI has received considerable attention..$^{1,3,5-8,10,11}$ The most common ECG changes associated with TC are ST-segment elevation and negative $\mathrm{T}$ waves., ${ }^{1,3,10-12}$ Previous studies have reported that negative $T$ waves already appear on initial ECGs in many patients with TC. ${ }^{2,12}$ One might misdiagnose such patients as reperfused anterior $\mathrm{AMI}^{5}$ and consider starting antiplatelet and anticoagulant therapy and performing CAG to decide whether coronary revascularization is required. In patients with TC, however, such treatment at presentation and subsequently is not only unnecessary, but also may increase the risk of bleeding because TC is often associated with acute events such as intracranial bleeding, head trauma, gastric ulcer, or surgery. ${ }^{1,2}$ In addition, most TC patients are elderly women, $1,2,4,6-14$ contributing to the risk of bleeding. Electrocardiographic criteria that can be used to differentiate TC from reperfused anterior AMI in the subacute phase are essential for selecting the most appropriate treatment strategy. To clarify the electrocardiographic differences between these 2 diseases in this phase, we studied homogeneous groups of patients. Previous studies have reported highly variable electrocardiographic findings in patients with TC. ${ }^{11,12}$ In those studies, the elapsed time from symptom onset to recording ECG varied widely, potentially contributing to the heterogeneity of electrocardiographic findings. Mitsuma et $\mathrm{al}^{9}$ reported that serial electrocardiographic changes of TC may reflect its clinical phase; perhaps ST-segment elevation is present in all patients early in the course of
$\mathrm{TC}$, and negative $\mathrm{T}$ waves appear subsequently. Therefore, our study included only TC patients who were admitted within $6 \mathrm{~h}$ of symptom onset and who had acute ST-segment elevation on admission ECG.

In this setting, negative $\mathrm{T}$ waves in $\mathrm{TC}$ initially deepened with greatest amplitude approximately 2 days after symptom onset, consistent with previous reports. ${ }^{1,9,10}$ Similar electrocardiographic changes were also observed in reperfused anterior AMI, but were especially prominent in TC. In patients with reperfused anterior AMI, the development of negative T waves in the subacute phase has been attributed to viable but sympathetically denervated myocardium, because sympathetic denervation delays repolarization. ${ }^{26-28}$ Our findings suggest that TC is associated with more extensive and more viable, but sympathetically denervated myocardium. Peak creatine kinase and creatine kinase-MB levels were significantly lower in patients with TC than in those with reperfused anterior AMI, despite left ventricular dysfunction in the acute phase. These findings also suggested that TC is associated with a greater mass of stunned myocardium.

To our knowledge, only the study reported by Kurisu et $\mathrm{al}^{10}$ scrutinized differences in negative $\mathrm{T}$ waves between $\mathrm{TC}$ and reperfused AMI. They compared electrocardiographic changes over time between 16 patients with TC and 15 patients with reperfused anterior AMI and a peak creatine kinase level $<1,000$ IU/L. However, changes in the negative $\mathrm{T}$ waves in the subacute phase were similar in both groups. Their study included only a small number of patients and assessed electrocardiographic changes in only leads $\mathrm{V}_{3,5}$ among all 12 leads. Moreover, they did not examine differences in the numbers or distributions of leads with negative $\mathrm{T}$ waves. We believe that our study is the first to show that TC is associated with deeper negative $\mathrm{T}$ waves and more leads with negative $\mathrm{T}$ waves, as well as a different distribution of negative $\mathrm{T}$ waves as compared with reperfused AMI, particularly non-Q-wave AMI. Generally, after ischemia and infarction, $T$ waves often become inverted in leads with previous ST-segment elevation. ${ }^{23}$ In patients with reperfused anterior AMI, negative T waves were distributed primarily around leads $V_{2-4}$, facing the anterior region. The extent of negative $\mathrm{T}$ waves in reperfused anterior AMI may be influenced by the extent of myocardial ischemic damage. In contrast, in patients with TC, negative $\mathrm{T}$ waves were more frequently and broadly distributed, as compared with reperfused anterior AMI. In the limb leads, the high prevalence of negative $\mathrm{T}$ waves was centered around lead $-\mathrm{a} V_{R}$. Lead $-a V_{R}\left(+30^{\circ}\right)$ bridges the gap between lead I $\left(0^{\circ}\right)$ and lead II $\left(60^{\circ}\right) ;^{23,24}$ in other words, lead $-\mathrm{aV}_{\mathrm{R}}$ faces the apical region. The frequency of negative $\mathrm{T}$ waves was high even in lead II and did not differ significantly from that in lead $-\mathrm{a} V_{\mathrm{R}}$, which had a frequency of $100 \%$. As compared with lead II, lead $-\mathrm{aVR}$ more directly faces the apical region. Consequently, lead $-\mathrm{a} V_{R}$ may more closely reflect the status of wall motion abnormalities centered around the apical region in patients with TC. In anterior AMI, the perfusion territory of the LAD coronary artery usually does not extend to these regions and so the prevalence of negative $\mathrm{T}$ waves in lead $-\mathrm{a} V_{\mathrm{R}}$ is relatively low. In contrast, the extent of negative $\mathrm{T}$ waves in $\mathrm{TC}$ is very broad, involving anterior, lateral, and inferior regions, as well as the apical region, which is beyond the perfusion territory of any single coronary artery. On the other hand, negative $\mathrm{T}$ waves less frequently appeared in leads $a V_{L}$ and $V_{1}$ and were particularly rare in lead $V_{1}$. These electrocardiographic findings are probably ascribed to the fact that wall motion abnormalities in TC rarely extend to the regions faced by these leads; ${ }^{1,29}$ lead $\mathrm{aV}_{\mathrm{L}}$ faces the upper lat- 
eral region, and lead $\mathrm{V}_{1}$ faces the right ventricular anterior region, as well as the right paraseptal region. ${ }^{30,31}$ Moreover, less negative $\mathrm{T}$ waves in lead $\mathrm{V}_{1}$ may be attributed to another reason. TC, but not anterior AMI, is usually associated with wall motion abnormalities in the posterolateral region, ${ }^{1,32}$ resulting in negative $\mathrm{T}$ waves in this region. This finding is reflected in the appearance of positive $\mathrm{T}$ waves in the opposing lead $\mathrm{V}_{1}{ }^{20,23,24} \mathrm{We}$ have previously shown that during the acute phase, TC is characterized by the presence of ST-segment elevation in lead $-\mathrm{aV} V_{R}$ and the absence of ST-segment elevation in lead $\mathrm{V}_{1}{ }^{6}$ During the subacute phase, it is plausible that these findings were reflected in the presence of negative $\mathrm{T}$ waves in lead $-\mathrm{a} V_{R}$ and the absence of negative $\mathrm{T}$ waves in lead $V_{1}$. The underlying reasons remain speculative, but in the present study these electrocardiographic findings most accurately predicted $\mathrm{TC}$.

\section{Study Limitations}

This study was retrospective and performed at a single center. Furthermore, we studied a relatively small number of patients who met strict inclusion criteria to ensure a homogeneous group of subjects. Consequently, our findings may not be able to be extrapolated to a general group of patients with TC and anterior AMI. Finally, caution is required because we retrospectively studied only ECGs with negative $\mathrm{T}$ waves of the greatest amplitude to assess the value of electrocardiographic findings for discriminating between TC and reperfused anterior AMI. Further studies of larger number of patients are needed to confirm our findings.

\section{Conclusions}

The development of negative $\mathrm{T}$ waves differed between TC and reperfused anterior AMI in the subacute phase. This observation may provide important clues to understanding the differences in underlying electrophysiologic mechanisms between TC and reperfused anterior AMI and facilitate the differential diagnosis of these 2 diseases.

\section{References}

1. Bybee KA, Prasad A. Stress-related cardiomyopathy syndromes. Circulation 2008; 118: 397-409.

2. Eitel I, von Knobelsdorff-Brenkenhoff F, Bernhardt P, Carbone I, Muellerleile K, Aldrovandi A, et al. Clinical characteristics and cardiovascular magnetic resonance findings in stress (takotsubo) cardiomyopathy. JAMA 2011; 306: 277-286.

3. Bybee KA, Kara T, Prasad A, Lerman A, Barsness GW, Wright RS, et al. Transient left ventricular apical ballooning: A syndrome that mimics ST-segment elevation myocardial infarction. Ann Intern Med 2004; 141: 858-865.

4. Hurst RT, Prasad A, Askew JW 3rd, Sengupta PP, Tajik AJ. Takotsubo cardiomyopathy: A unique cardiomyopathy with variable ventricular morphology. JACC Cardiovasc Imaging 2010; 3: 641-649.

5. Ibanez B, Benezet-Mazuecos J, Navarro F, Farre J. Takotsubo syndrome: A Bayesian approach to interpreting its pathogenesis. Mayo Clin Proc 2006; 81: 732-735.

6. Kosuge M, Ebina T, Hibi K, Morita S, Okuda J, Iwahashi N, et al. Simple and accurate electrocardiographic criteria to differentiate takotsubo cardiomyopathy from anterior acute myocardial infarction. $J$ Am Coll Cardiol 2010; 55: 2514-2516.

7. Ogura R, Hiasa Y, Takahashi T, Yamaguchi K, Fujiwara K, Ohara $Y$, et al. Specific findings of the standard 12-lead ECG in patients with 'Takotsubo' cardiomyopathy: Comparison with the findings of acute anterior myocardial infarction. Circ J 2003; 67: 687-690.

8. Inoue M, Shimizu M, Ino H, Yamaguchi M, Terai H, Fujino N, et al. Differentiation between patients with takotsubo cardiomyopathy and those with anterior acute myocardial infarction. Circ J 2005; 69: 8994.

9. Mitsuma W, Kodama M, Ito M, Tanaka K, Yanagawa T, Ikarashi N, et al. Serial electrocardiographic findings in women with Takotsubo cardiomyopathy. Am J Cardiol 2007; 100: 106-109.

10. Kurisu S, Inoue I, Kawagoe T, Ishihara M, Shimatani Y, Nakamura $\mathrm{S}$, et al. Time course of electrocardiographic changes in patients with tako-tsubo syndrome: Comparison with acute myocardial infarction with minimal enzymatic release. Circ J 2004; 68: 77-81.

11. Sharkey SW, Lesser JR, Menon M, Parpart M, Maron MS, Maron BJ. Spectrum and significance of electrocardiographic patterns, troponin levels, and thrombolysis in myocardial infarction frame count in patients with stress (tako-tsubo) cardiomyopathy and comparison to those in patients with ST-elevation anterior wall myocardial infarction. Am J Cardiol 2008; 101: 1723-1728.

12. Dib C, Asirvatham S, Elesber A, Rihal C, Friedman P, Prasad A. Clinical correlates and prognostic significance of electrocardiographic abnormalities in apical ballooning syndrome (Takotsubo/stress-induced cardiomyopathy). Am Heart J 2009; 157: $933-938$.

13. Sharkey SW, Windenburg DC, Lesser JR, Maron MS, Hauser RG, Lesser JN, et al. Natural history and expansive clinical profile of stress (tako-tsubo) cardiomyopathy. J Am Coll Cardiol 2010; 55: 333-341.

14. Tsuchihashi K, Ueshima K, Uchida T, Oh-mura N, Kimura K, Owa $\mathrm{M}$, et al. Transient left ventricular apical ballooning without coronary artery stenosis: A novel heart syndrome mimicking acute myocardial infarction: Angina Pectoris-Myocardial Infarction Investigations in Japan. J Am Coll Cardiol 2001; 38: 11-18.

15. Steffel J, Hürlimann D, Namdar M, Despotovic D, Kobza R, Wolber $\mathrm{T}$, et al. Long-term follow-up of patients with isolated left ventricular noncompaction: Role of electrocardiography in predicting poor outcome. Circ J 2011; 75: 1728-1734.

16. Ibanez B, Choi BG, Navarro F, Farre J. Tako-tsubo syndrome: A form of spontaneous aborted myocardial infarction? Eur Heart $J$ 2006; 27: 1509-1510.

17. Delgado GA, Truesdell AG, Kirchner RM, Zuzek RW, Pomerantsev $\mathrm{EV}$, Gordon PC, et al. An angiographic and intravascular ultrasound study of the left anterior descending coronary artery in takotsubo cardiomyopathy. Am J Cardiol 2011; 108: 888-891.

18. Haghi D, Roehm S, Hamm K, Harder N, Suselbeck T, Borggrefe M, et al. Takotsubo cardiomyopathy is not due to plaque rupture: An intravascular ultrasound study. Clin Cardiol 2010; 33: 307-310.

19. Thygesen K, Alpert JS, White HD; Joint ESC/ACCF/AHA/WHF Task Force for the Redefinition of Myocardial Infarction. Universal definition of myocardial infarction. Circulation 2007; 116: 26342653.

20. The TIMI study group. The thrombolysis in myocardial infarction (TIMI) trial: Phase I findings. N Eng J Med 1985; 312: 932-936.

21. Yamaji H, Iwasaki K, Kusachi S, Murakami T, Hirami R, Hamamoto $\mathrm{H}$, et al. Prediction of acute left main coronary artery obstruction by 12-lead electrocardiography: ST segment elevation in lead aVR with less ST segment elevation in lead V1. J Am Coll Cardiol 2001; 38: $1348-1354$.

22. Kunishima T, Akashi YJ, Miyake F, Aoyama N, Kohshoh H, Yoshino $\mathrm{H}$, et al. The T wave inversion score is useful for evaluating the timecourse of acute pulmonary embolism. Circ J 2011; 75: 1222-1226.

23. Wagner GS, Macfarlane P, Wellens H, Josephson M, Gorgels A, Mirvis DM, et al. AHA/ACCF/HRS recommendations for the standardization and interpretation of the electrocardiogram. Part VI: Acute ischemia/infarction: A scientific statement from the American Heart Association Electrocardiography and Arrhythmias Committee, Council on Clinical Cardiology; the American College of Cardiology Foundation; and the Heart Rhythm Society: Endorsed by the International Society for Computerized Electrocardiology. J Am Coll Cardiol 2009; 53: 1003-1011.

24. Kligfield P, Gettes LS, Bailey JJ, Childers R, Deal BJ, Hancock EW, et al. Recommendations for the standardization and interpretation of the electrocardiogram. Part I: The electrocardiogram and its technology: A scientific statement from the American Heart Association Electrocardiography and Arrhythmias Committee, Council on Clinical Cardiology; the American College of Cardiology Foundation; and the Heart Rhythm Society. Circulation 2007; 115: 1306-1324.

25. Bazett HC. An analysis of the time relations of electrocardiograms. Heart 1920; 7: 353-370.

26. Matetzky S, Barabash GI, Shahar A, Rabinowitz B, Rath S, Zahav $\mathrm{YH}$, et al. Early T wave inversion after thrombolytic therapy predicts better coronary perfusion: Clinical and angiographic study. $J \mathrm{Am}$ Coll Cardiol 1994; 24: 378-383.

27. Agetsuma H, Hirai M, Hirayama H, Suzuki A, Takanaka C, Yabe S, et al. Transient giant negative $\mathrm{T}$ wave in acute anterior myocardial infarction predicts $\mathrm{R}$ wave recovery and preservation of left ventricular function. Heart 1996; 75: 229-234.

28. Inoue H, Zipes DP. Time course of denervation of efferent sympathetic and vagal nerves after occlusion of the coronary artery in the canine heart. Circ Res 1988; 62: 1111-1120. 
29. Haghi D, Athanasiadis A, Papavassiliu T, Suselbeck T, Fluechter S, Mahrholdt H, et al. Right ventricular involvement in Takotsubo cardiomyopathy. Eur Heart J 2006; 27: 2433-2439.

30. Ben-Gal T, Sclarovsky S, Herz I, Strasberg B, Zlotikamien B, Sulkes $\mathrm{J}$, et al. Importance of the conal branch of the right coronary artery in patients with acute anterior wall myocardial infarction: Electrocardiographic and angiographic correlation. J Am Coll Cardiol 1997; 29: 506-511.

31. Geft IL, Shah PK, Rodriguez L, Hulse S, Maddahi J, Berman DS, et al. ST elevations in leads $\mathrm{V}_{1}$ to $\mathrm{V}_{5}$ may be caused by right coronary artery occlusion and acute right ventricular infarction. Am J Cardiol 1984; 53: 991-996.

32. Patel SM, Lennon RJ, Prasad A. Regional wall motion abnormality in apical ballooning syndrome (Takotsubo/stress cardiomyopathy): Importance of biplane left ventriculography for differentiating from spontaneously aborted anterior myocardial infarction. Int J Cardiovasc Imaging 2011 [Epub ahead of print]. 